\title{
NÍVEIS DE RACTOPAMINA E SUA INFLUÊNCIA SOBRE O DESEMPENHO E CARACTERÍSTICAS DE CARCAÇA DE SUÍNOS EM TERMINAÇÃO
}

Helena Maria Fonseca da Silva'; Letícia Gomes de Morais Amaral'; Nikolas de Oliveira Amaral²; Fábio Ribeiro de Almeida ${ }^{3}$; Gustavo Freixo Rodrigues ${ }^{4}$; Rogério Rudolfo Heinemann ${ }^{1}$; Ana Paula Cardoso Gomide ${ }^{5}$

${ }^{1}$ Estudante de Mestrado em zootecnia no Intituto Federal Goiano-Campus Rio Vrede. ${ }^{2}$ Professor (a) Instituto Federal Sul de Minas, Campus Machado, MG. ${ }^{3}$ Engenheiro Agrônomo formado pelo Instituto Federal do Sul de Minas-Campus Machado. ${ }^{4}$ Estudante de Graduação em zootecnia no Instituto Federal do Sul de Minas-Campus Machado. ${ }^{5}$ Professor(a) Instituto Federal Goiano, Campus Rio Verde, GO. E-mail: helenafds@hotmail.com

\section{RESUMO}

Aumentar a quantidade de carne na carcaça de suínos tem sido o objetivo não somente da indústria, como também do produtor de suínos, uma vez que melhora a rentabilidade e diminui os custos de produção. Neste sentido, objetivou-se com essa pesquisa avaliar o desempenho e as características de carcaça de suínos em terminação suplementados com diferentes níveis de ractopamina na dieta. Foram utilizados 60 suínos (30 machos castrados e 30 fêmeas), com peso inicial médio de 75,0 $\mathrm{Kg}$ alojados em baias de piso parcialmente ripado. O delineamento experimental foi em blocos casualizados com três níveis de ractopamina - 0, 5 e $10 \mathrm{ppm}$, totalizando três tratamentos e dez repetições, com dois animais (um macho e uma fêmea) por baia (parcela experimental). Foram realizadas análises de desempenho (peso final, ganho de peso médio diário, consumo de ração médio diário e conversão alimentar) e de qualidade de carcaça (rendimento de carcaça, rendimento de carne na carcaça, espessura de toucinho e profundidade de lombo). A suplementação de $10 \mathrm{ppm}$ de ractopamina na dieta de suínos em terminação aumentou o rendimento de carne na carcaça e reduziu a espessura de toucinho. Assim, conclui-se que a suplementação de 10 ppm de ractopamina na dieta de suínos em terminação melhora as características de carcaça.

Palavras chave: nutrição; qualidade de carcaça; suinocultura.

\section{RACTOPAMINE LEVELS AND ITS INFLUENCE ON PERFORMANCE AND CARCASS CHARACTERISTICS OF FINISHING PIGS}

\begin{abstract}
Increasing the amount of meat in the pig carcass has been the goal not only of the industry but also of the pig producer as it improves profitability and reduces production costs. In this sense, the objective of this research was to evaluate the performance and carcass characteristics of finishing pigs supplemented with different levels of ractopamine in the diet. Sixty 60 pigs (30 castrated males and 30 females) were used, with a mean initial weight of $75.0 \mathrm{~kg}$ housed in partially slatted stalls. The experimental design was a randomized block with three ractopamine levels $(0,5$ and $10 \mathrm{ppm})$, totaling three treatments and ten replicates, with two animals (one male and one female) per pen (experimental plot). There were analyzed animals performance (final weight, average daily weight gain, daily feed intake and feed conversion) and carcass quality (carcass yield, carcass meat yield, backfat thickness and loin depth). The supplementation of $10 \mathrm{ppm}$ of ractopamine in the finishing pig diet increased the meat yield in the carcass and reduced the backfat thickness. Thus, it is concluded that the supplementation of $10 \mathrm{ppm}$ of ractopamine in the finishing pig diet improves the carcass traits.
\end{abstract}

Keywords: nutrition; carcass quality; swine breeding;

\section{INTRODUÇÃO}

O aumento da quantidade de carne na quantidade de carne na carcaça de suínos tem sido o objetivo não somente da indústria, como também dos produtores de suínos terminados, visando melhorar a rentabilidade e diminuir os 
custos de produção. Além disso, do ponto de vista do frigorífico, é interessante agregar valor aos produtos, de forma a aumentar a lucratividade.

Neste sentido, um aditivo que vem sendo bastante utilizado na dieta de suínos em terminação é a ractopamina. Uma vez que a suplementação com ractopamina na dieta pode promover maior deposição de músculo e menor deposição de gordura na carcaça suína, devido ao aumento da lipólise em detrimento da lipogênese em animais na fase final de terminação. Segundo Aalhus et al. (1992) esta substância liga-se aos receptores das membranas celulares promovendo aumento no diâmetro das fibras musculares e, simultaneamente, diminuição na lipogênese e aumento na lipólise.

Segundo Haese e Bunzen (2005) sugerem que os efeitos atribuídos à ractopamina são os aumentos da atividade lipolítica e inibição da lipogênese, pois a ractopamina inibe a ligação da insulina no receptor adrenérgico dos adipócitos, e assim, antagoniza a ação da insulina, diminuindo a síntese e a deposição de gordura nos suínos.

De acordo com Amaral et al. (2009) vários autores têm relatado o efeito benéfico da ractopamina no desempenho e características de carcaça dos suínos por meio do aumento no ganho de peso, redução no consumo de ração, melhoria na eficiência alimentar e do rendimento de carne magra.

Com relação ao nível de suplementação, de acordo com Shinckel et al. (2001) am resposta à ractopamina, para melhorar o ganho de peso médio diário pode ser alcançada com uma concentração dietética de $5 \mathrm{ppm}$. Porém, de acordo com os autores, níveis mais altos, como por exemplo 10 a $20 \mathrm{ppm}$, podem maximizar a deposição muscular na carcaça e a eficiência de utilização dos nutrientes.

Pelo exposto, objetivou-se com este estudo avaliar o desempenho e as características de carcaça de suínos em terminação suplementados com diferentes níveis de ractopamina na dieta.

\section{MATERIAL E MÉTODOS}

\section{Local de realização do experimento}

A pesquisa foi conduzida na Unidade Educativa de Produção de Suínos do Instituto Federal de Educação, Ciência e Tecnologia do Sul de Minas Gerais (IFSULDEMINAS), Campus Machado - MG.

\section{Animais e instalações}

A metodologia aplicada no presente estudo foi aprovada pelo Comitê de Ética no Uso de Animais (CEUA) da UNIFENAS, parecer no 06/A 2014.

Foram utilizados 30 suínos machos castrados e 30 fêmeas, com peso inicial de $\pm 75,0$ $\mathrm{Kg}$ alojados em baias com dois animais (parcela experimental), em instalações de crescimento e terminação com baias de piso de concreto $(2,0 \mathrm{x}$ $1,5 \mathrm{~m}^{2}$ ) parcialmente ripado, dotadas de comedouros manuais e bebedouros tipo chupeta.

\section{Delineamento experimental}

O delineamento experimental foi em blocos casualizados com três níveis de ractopamina $-0,5$ e $10 \mathrm{ppm}$, totalizando três tratamentos e dez repetições, com dois animais (um macho e uma fêmea) por parcela experimental.

\section{Procedimento experimental}

Antes do início do experimento foram obedecidas as normas usuais para limpeza e desinfecção do galpão de 17 dias, sendo dois para limpeza e 15 para vazio sanitário com pulverização de desinfetante a base de amônia quaternária e glutaraldeído.

As dietas foram formuladas a base de milho e farelo de soja, suplementadas com vitaminas e minerais de forma a atender as exigências mínimas sugeridas por (ROSTAGNO et al., 2011), com exceção da lisina.

Dietas e água foram fornecidas à vontade, durante todo o período experimental que teve duração de 28 dias. Os suínos foram pesados no início e no final do experimento, para a determinação do ganho de peso. Diariamente, foi realizada a limpeza das baias e, duas vezes ao dia, a ração foi fornecida e os desperdícios foram pesados para a determinação do consumo de cada animal. A conversão alimentar foi obtida por meio da relação entre o consumo de ração e o ganho de peso neste período.

As variáveis analisadas para o desempenho foram peso final, consumo de ração médio diário, ganho de peso médio diário e conversão alimentar.

Após 28 dias de suplementação com ractopamina, os animais foram submetidos ao jejum sólido por no máximo 12 horas. Após o 
jejum, um animal macho de cada parcela foi pesado, abatido e eviscerado para a avaliação da carcaça. Logo após a evisceração, as carcaças foram serradas longitudinalmente ao meio e pesadas. A meia carcaça esquerda de cada suíno foi resfriada a uma temperatura média de $7 \stackrel{\circ}{\circ}$, durante 24 horas, para posterior avaliação das características da mesma. As variáveis analisadas foram o rendimento de carcaça, espessura de toucinho, rendimento de carne na carcaça e profundidade de lombo. A determinação do rendimento de carne na carcaça resfriada foi realizada por meio de análise de predição conforme a fórmula descrita por Guidoni (2000).

Os dados referentes à origem dos animais avaliados, bem como os referentes às demais atividades de gerenciamento da Unidade Educativa foram registrados e analisados através do software Agriness S2 Comercial.

\section{Análises estatísticas}

Os dados foram avaliados quanto a sua normalidade pelo teste estatístico Shapiro-Wilk (SAS, 2009). Uma vez comprovada a normalidade foi realizada a análise de variância e as médias comparadas pelo teste Tukey com $5 \%$ de significância.

\section{RESULTADOS E DISCUSSÃO}

Os resultados de desempenho estão descritos na tabela a seguir (Tabela 1).

Tabela 1. Desempenho de suínos de em terminação suplementados com diferentes níveis de ractopamina na dieta $(0,5$ e $10 \mathrm{ppm})$

\begin{tabular}{lcccc}
\hline \multirow{2}{*}{ Variável } & \multicolumn{3}{c}{ Níveis de ractopamina } & \multirow{2}{*}{$\begin{array}{c}\text { CV } \\
\text { (\%) }\end{array}$} \\
\cline { 2 - 4 } Peso Inicial (Kg) & $0 \mathrm{ppm}$ & $5 \mathrm{ppm}$ & $10 \mathrm{ppm}$ & \\
Peso Final (Kg) & 72,03 & 71,99 & 72,26 & 1,23 \\
Ganho de Peso Médio Diário (Kg) & 100,96 & 101,31 & 101,95 & 3,25 \\
Consumo de Ração Médio Diário (Kg) & 1,03 & 1,05 & 1,06 & 10,48 \\
Conversão Alimentar & 2,84 & 2,75 & 2,72 & 7,39 \\
\hline
\end{tabular}

Não foram observadas diferenças significativas $(P>0,05)$ para a suplementação de ractopamina, independentemente do nível de administração. Esses resultados divergem da maioria dos trabalhos como Amaral et al. 2009 e Garbossa et al. (2013), que verificaram o efeito linear em animais suplementados com ractopamina.

Porém, alguns trabalhos corroboram com o resultado encontrado, como, Pereira et al. (2008), trabalhando com adição da ractopamina (zero e cinco ppm) e dois níveis de lisina digestível $(0,67$ e $0,87 \%)$ na dieta fornecida por tempos diferentes, 21 e 28 dias, não evidenciaram resposta nesses períodos estudados. Sanches et al. (2010), avaliando suínos machos castrados em terminação, recebendo os níveis de zero, cinco, 10 e 20 ppm de ractopamina, não verificaram efeito sobre o peso final. Mimbs et al. (2005), utilizando até 10 ppm de ractopamina para suínos em terminação, não observaram diferença no peso final.

Com relação às características de carcaça, etes estão descritos na tabela a seguir (Tabela 2).

Tabela 2. Avaliação de carcaça de suínos aos $100 \mathrm{Kg}$ alimentados com diferentes níveis de ractopamina na dieta (0, 5 e 10 ppm)

\begin{tabular}{lcccc}
\hline \multirow{2}{*}{ Variável } & \multicolumn{3}{c}{ Níveis de ractopamina } & CV \\
\cline { 2 - 3 } & $0 \mathrm{ppm}$ & $5 \mathrm{ppm}$ & $10 \mathrm{ppm}$ & $(\%)$ \\
\hline Rendimento de Carcaça (\%) & 76,74 & 77,34 & 78,50 & 4,39 \\
Rendimento de Carne na Carcaça (\%) & $61,17 \mathrm{a}$ & $62,21 \mathrm{ab}$ & $62,81 \mathrm{~b}$ & 2,42 \\
Espessura de toucinho (mm) & $12,21 \mathrm{~b}$ & $11,20 \mathrm{ab}$ & $10,20 \mathrm{a}$ & 17,97 \\
Profundidade de Lombo (mm) & 61,18 & 64,93 & 64,57 & 7,51 \\
\hline
\end{tabular}

*Médias seguidas de letras diferentes na linha diferem entre si pelo teste Tukey $(P<0,05)$. 
A suplementação com $10 \mathrm{ppm}$ de ractopamina resultou em melhoria do rendimento de carne na carcaça e da espessura de toucinho. Em relação aos animais não suplementados, foi observado acréscimo de $2,7 \%$ no rendimento de carne na carcaça e redução de $16,5 \%$ na espessura de toucinho. Estes resultados demonstram a eficiência da ractopamina como partidor de nutrientes, aumentando a taxa de deposição proteica (aumento do rendimento de carne na carcaça) e diminuindo a deposição de gordura na carcaça (redução na espessura de toucinho).

Estes resultados corroboram com os de Marinho et al. (2007) em que a adição de ractopamina durante 28 dias resultou em menor $(P<0,05)$ espessura de toucinho, ou seja, os animais alimentados com dietas com 5 ppm de ractopamina apresentaram espessura de toucinho $7,5 \%$ menor em relação àqueles que não receberam suplementação, cuja redução de $0,9 \mathrm{~mm}$ na espessura de toucinho correspondeu à melhora de $8,11 \%$ na espessura de toucinho decorrente da adição de cinco ppm de ractopamina na dieta. Resultados semelhantes foram obtidos também por Jones et al. (1988) e Mitchell et al. (1990).

Já os resultados de Adeola et al. (1990), Stites et al. (1991) e Pozza et al. (2003) não verificaram efeito significativo da adição de ractopamina sobre a espessura de toucinho.

Para a profundidade de lombo, os trabalhos de Adeola et al. (1990) e Aalhus et al. (1990) corroboram com os resultados em que não verificaram efeitos positivos da suplementação de ractopamina sobre a profundidade de lombo.

Já os autores, Marinho et al. (2007) e Gu et al. (1991) encontraram que profundidade de lombo aumentou $(P<0,05) \quad 2,8$ e $3,9 \mathrm{~mm}$, correspondente a 4,91 e 6,5\%, com a adição de ractopamina durante 21 e 28 dias, respectivamente.

\section{CONCLUSÃO}

A suplementação de $10 \mathrm{ppm}$ de ractopamina na dieta de suínos em terminação aumenta o rendimento de carne na carcaça e reduz a espessura de toucinho.

\section{AGRADECIMENTOS}

Agradecemos ao Instituto Federal do Sul de Minas Gerais - Campus Machado pela concessão das instalações experimentais e bolsas de estudo; e à empresa Agriness LTDA, pela disponibilização do software Agriness S2.

\section{REFERÊNCIAS}

AALHUS, J.L.; JONES, S.D.M.; SCHAEFER, A.L.; TONG, A.K.W.; ROBERTSON, W.M.; MURRAY, A.C.; MERRILL, J.K. The effect of ractopamine on performance, carcass composition and meat quality of finishing pigs. Canadian Journal of Animal Science, v.70, n.5, p.943-952, 1990. https://doi.org/10.4141/cjas90-113

AALHUS, J.L.; SCHAEFER, A.L.; MURRAY, A.C. JONES, S.D.M. The effect of ractopamine on myofibre distribution and morphology and their relation to meat quality in swine. Meat Science, v.31, p.97-409, 1992. https://doi.org/10.1016/0309-1740(92)90023-W

ADEOLA, O.; DARKO, E.A.; HE, P.; YOUNG, L.G. Manipulation of porcine carcass composition by ractopamine. Journal of Animal Science,v.68, n.11, p.3633-3641, 1990. https://doi.org/10.2527/1990.68113633x

AMARAL, N.O.; FIALHO, E.T.; CANTARELLI, V. S.; ZANGERONIMO, M.G.; RODRIGUES, P.B.; GIRÃO, L. V.C. Ractopamine hydrochloride in formulated rations for barrows or gilts from 94 to $130 \mathrm{~kg}$. Revista Brasileira de Zootecnia, v. 38, p. 14941501, 2009. https://doi.org/10.1590/S1516$\underline{35982009000800013}$

GARBOSSA, C.A.P.; CANTARELLI, V. de S.; SOUSA, R.V.; CANTARELLI, V.S.; PIMENTA, M.E.S.G.; ZANGERONIMO, M.G.; SILVEIRA, H.; KURIBAYASHI, T.H.; CERQUEIRA, L.G.S. Ractopamine levels on performance, carcass characteristics and quality of pig meat. Revista Brasileira de Zootecnia (Online), v.42, p.325-333, 2013. https://doi.org/10.1590/S1516$\underline{35982013000500004}$

GU, Y.; SCHINCKEL, A.P.; FORREST, J.C.; KUEI, C.H.; WATKINS, L.E. Effects of ractopamine, genotype, and growth phase on finishing performance and carcass value in swine: II. Estimation of lean growth rate and lean feed efficiency. Journal of Animal Science,v.69, n.7, p.2694-2702, 1991. https://doi.org/10.2527/1991.6972694x 
GUIDONI, A. L. Melhoria de processos para a tipificação e valorização de carcaças suínas no Brasil. In: CONF. INT. VIRTUAL SOBRE QUAL. DE CARNE SUÍNA. Anais... Concórdia: Embrapa Suínos e Aves, 2000. 14p.

HAESE, D.; BUNZEN, S. Ractopamina Nutritime, v.2, mar. 2005. Disponível em: <http://www.nutritime.com.br>. Acesso em: 20 Fev. 2017.

JONES, D.J.; WAITT, W.P.; MOWREY, D.H. et al. Effect of ractopamine hydrochloride on growth performance and carcass composition of finisher pigs fed corn-soy diets with $5 \%$ added fat. Journal of Animal Science, v.66, p.324 (Abst. 255, Suppl. 1), 1988.

MARINHO, P.C.; FONTES, D.O.; SILVA, F.C.O.; SILVA, M.A.; PEREIRA, F.A.; AROUCA, C.L.C. Effects digestible lysine levels and of ractopamine on the performance and carcass characteristics of finishing barrows. Revista Brasileira de Zootecnia, v.36, n.6, p.1791-1798, 2007. https://doi.org/10.1590/S1516-

35982007000800012

MIMBS, K. J.; PRINGLE, T. D.; AZAIN, M. J.; MEERS, S. A.; ARMSTRONG, T. A. Effects of ractopamine on performance and composition of pigs phenotypically sorted into fat and lean groups. Journal of Animal Science, v.83, n.6, p.13611369, 2005. https://doi.org/10.2527/2005.8361361x

MITCHELL, A.D.; SOLOMON, M.B.; STEELE, N.C. Response of low and high protein select lines of pigs to the feeding of the beta-adrenergic agonist ractopamine (phenethanolamine). Journal of Animal Science, v.68, n.10, p.3226-3232, 1990. https://doi.org/10.2527/1990.68103226x

PEREIRA, F.A.; FONTES, D.O.; SILVA, F.C.O.; FERREIRA, W.M.; LANNA, A.M.Q.; CORRÊA, G.S.S.; SILVA, M.A.; MARINHO, P.C.; AROUCA, C.L.C.; SALUM, G.M. Efeitos da ractopamina e de dois níveis de lisina digestível na dieta sobre o desempenho e características de carcaça de leitoas em terminação. Arquivo Brasileiro de Medicina Veterinária e Zootecnia, v.60, n.4, p.943-952, 2008. https://doi.org/10.1590/S0102$\underline{09352008000400025}$
POZZA, P.C.; SANTOS, M.S.; NUNES, R.V.; OELKE, C.A.; SOUZA, F.H.; PETRY, L.; DUNKE, L.J. Avaliação da suplementação de Ractopamina sobre o desempenho e características de carcaça de suínos fêmeas na fase de terminação. In: CONGRESSO BRASILEIRO DE VETERINÁRIOS ESPECIALISTAS EM SUÍNOS, 11., 2003, Goiânia. Anais... Goiânia: ABRAVES, 2003. p.291292.

ROSTAGNO, H. S.; ALBINO, L. F. T.; DONZELE, J .L.; GOMES, P. C.; OLIVEIRA, R. F.; LOPES, D. C.; et al. Tabelas brasileiras para aves e suínos: composição de alimentos e exigências nutricionais de aves e suínos. 3. ed. Viçosa: UFV, 2011. $252 \mathrm{p}$.

SANCHES, J.F.; KIEFER, C.; MOURA, M.S.; SILVA, C.M.; LUZ, M.F.; CARRIJO, A.S. Níveis de ractopamina para suínos machos castrados em terminação e mantidos sob conforto térmico. Ciência Rural, v.40, n.2, p.403-408, 2010.

SAS INSTITUTE. User's guide statistics. Version 9.3. Cary, 2009.

STITES, C.R.; MCKEITH, F.K.; SINGH, S.D. et al. The effect of ractopamine hydrochloride on the carcass cutting yields of finishing swine. Journal of Animal Science, v.69, n.8, p.3094-3101, 1991. https://doi.org/10.2527/1991.6983094x

Recebido para publicação em 15/08/2017

Revisado em 05/12/2018

Aceito em 04/04/2018 